\title{
INFÂNCIAS MÚLTIPLAS NA COLEÇÃO VIAGENS COM A CABAÇA MÁGICA DE ANGELINA NEVES
}

Eliane Santana Dias Debus

Zâmbia Osório dos Santos

Resumo: Este artigo busca trazer à cena a produção literária da escritora moçambicana Angelina Neves, em particular a Coleção Viagens com a cabaça mágica, um conjunto de 11 títulos. Diante disso, analisa-se aqui os três primeiros títulos, datados da década de 1990, a saber: Na aldeia de Chai, em Cabo Delgado (NEVES, 1996a); Em Inhambane fui apanhar tangerinas (NEVES, 1996b); Em Gaza fui saber sobre Ngungunhana (NEVES, 1999a). Nesta reflexão, busca-se trazer as características da Coleção, demarcar a representação de infância nas personagens e na projeção de leitores, na construção de uma Moçambique independente pós-guerra civil.

Palavras-chave: Moçambique. Infância. Literatura.

Abstract: This article seeks to bring to the scene the literary production of the Mozambican writer Angelina Neves, in particular the Collection Travels with the magic gourd, a set of 11 titles. Therefore, the first three titles, dating from the 1990s, are analyzed here: In the village of Chai, Cabo Delgado (NEVES, 1996a); In Inhambane I went to pick tangerines (NEVES, 1996b); In Gaza I learned about Ngungunhana (NEVES, 1999a). In this reflection, we seek to bring the characteristics of the Collection, demarcate the representation of childhood in the characters and in the projection of readers, in the construction of an independent post-civil war Mozambique.

Keywords: Mozambique. Childhood. Literature.

\section{Angelina Neves e a sua produção para infâncias}

Atenta! Não adormeço

Estou consciente dos sinais

Respiro esta jornada

Absorvo e processo 
Ando sem destino, sem fim à vista...

perco-me ... e, por vezes, maravilho-me! Angelina Neves

Escolher o poema "Atenta", de Angelina Neves, para adentrar em texto que busca apresentá-la e a sua obra, em particular a Coleção Viagens com a cabaça mágica, parecenos oportuno, em particular, essa estrofe que diz muito da escritora-educadora, que, consciente aos sinais e atenta às demandas do seu tempo, desenvolve uma farta produção para infância, "sem fim à vista", sempre com a capacidade de maravilhar-se.

Angelina Neves nasceu em 14 de julho de 1951, em Maputo (ex-Lourenço Marques), e seu espírito aventureiro e apurado senso coletivo humanitário levou-a a aderir o desejo de independência e a trabalhar no país pós-independência (1975), em particular, pós-guerra civil (1991), momento que se volta ao trabalho com a infância. Uma infância dividida/ repartida entre aquela órfã da guerra, abandonada, fugida do espaço familiar ou da fome e aquela das "crianças soldados", segundo Neves, (2010, s.p.), “[...] vítimas dos loucos dos adultos e das suas guerras inglórias [...]".

No início da década de 1990, a escritora-educadora começa a se dedicar a produção de livros para infância: 
livros com fins didáticos, literários e de recreação (Boletins informativos), entre outros. Grande parte das publicações é em parceria com organizações humanitárias, como a Organização das Nações Unidas para a Educação, a Ciência e a Cultura (UNESCO) e Save the Children, das quais recebeu prêmios devido ao seu compromisso político com os direitos da infância em seu país.

Segundo Simone Caputo Gomes (2018), a "emergência" de uma produção para infância e juventude em Moçambique se dá pós-independência e,

[...] para início de uma sistematização, poderíamos descrever três fases, a primeira cobre os anos de 1979 a 1990; a segunda de 1991 a 2010; terceira de 2010 até os dias atuais. No entanto, faz-se necessário destacar que essa demarcação não é estanque, pois algumas/alguns escritoras/ escritores tiveram o seu exercício em ambos os momentos, como Angelina Neves. (DEBUS, 2021, p. 188)

Maria Anória de Oliveira (2011, p. 83), ao dialogar sobre as produções para infância em Moçambique, traz dois momentos, um situado no final dos anos de 1970 e outro no "renascimento da literatura infantil" nos anos de 1990, inserindo Angelina Neves como a precursora, elencando o "[...] folheto do jornal Njingiritane, destinado às crianças 
e jovens" como parte importante dessa dinâmica. O Suplemento Infantil Njingiritane, encartado no semanário Domingo, tem existência longa, haja vista que circula em Moçambique até os dias de hoje.

Angelina Neves foi convidada por Jorge Rebelo, membro no período do Comitê Político Militar da Frente de Libertação de Moçambique (Frelimo) e responsável pela informação do país, para organizar um espaço no boletim que contemplasse também contos para a leitura das crianças: "Esse exercício de escrita contínua no suplemento, provavelmente, leva a escritora a dar continuidade a sua produção" (DEBUS, 2021, p. 189).

No processo de sistematização da obra de Neves dedicadas à infância, elencamos três categorias principais: 1) produção didático-informativa; 2) recontos; 3) narrativas contemporâneas (DEBUS; SANTOS; GUILA, 2021). No primeiro, destacamos os livros Vamos contar? (NEVES, 2003) e A capulana de D. Filomena: Livro didáctico para o ensino inicial (NEVES; NUVUNGA, 2013) com narrativas seguidas ou combinadas de propostas para educadoras/es desenvolverem com crianças; no segundo, destacamos $O$ Coelho e a Hiena (NEVES, 2012a) e O Coelho e o Macaco (NEVES, 2012b), que integram uma coleção nomeada Histórias Tradicionais dos Grupos Linguísticos de Cabo Delgado, uma província ao norte 
de Moçambique; e encontra-se entre os títulos que compõe a terceira categoria os 11 títulos da coleção Viagens com a Cabaça Mágica, títulos que farão parte desta análise.

\section{Coleção Viagens com a cabaça mágica: aspectos gerais}

A Coleção Viagens com a Cabaça Mágica é constituída por 11 volumes e em cada um temos uma narrativa que envolve uma das 11 províncias de Moçambique, seguindo sua divisão política e administrativa: Cabo Delgado, Niassa, Nampula, Tete, Manica, Sofala, Zambézia, Inhambane, Gaza, Maputo e a capital, também denominada de Maputo, pois tem estatuto de província. Angelina Neves idealizou a coleção, construiu as narrativas e ilustrou algumas passagens dos volumes, mas podemos dizer que é a feitura de um trabalho coletivo com Razac e Humberto, responsáveis por parte significativa das ilustrações. O primeiro deteve-se nas personagens - poderíamos dizer a parte contemporânea da narrativa -; o segundo, a parte histórica - o passado. Além da colaboração de António Sopa na pesquisa histórica por meio de documentos e a inserção de dados factuais.

A coleção foi publicada entre os anos de 1996 a 2001, financiada pela Fundação Bernard van Leer, criada em 1949 e sediada na Holanda, a qual tem o foco de seus financiamentos na infância, e editada pela Coopimagem. Cada volume teve a 
impressão de 10 mil exemplares, que foram distribuídos nas 11 províncias de Moçambique, entre os anos de 1996 até 2001. Os livros possuíam o mesmo formato, ou seja, $20 \mathrm{~cm} X 30 \mathrm{~cm}$, há alternância nas fontes utilizadas entre letra cursiva e letra impressa, que fica visível nas ilustrações Razac (presente), Humberto (passado) e Angelina Neves (ficcional). A linguagem verbal e visual está distribuída nas 36 páginas de cada volume.

A tipografia escolhida dialoga com a noção literária de que Sura, a personagem, tem a autoria das narrativas. A fonte em letra cursiva funciona como um "texto não verbal", que dá verossimilhança à escrita no diário, possibilitando ler os registros de Sura das histórias sobre as viagens feitas com a cabaça mágica.

Figura 1 - Trecho do livro Em Tete fomos até Cabora Bassa (1999b)

(1) meu avò disse que os dois tinham razäo, mas que o methor era eu ir a Tele e depois tirar as minhas conclusões! Deu-me a Cabaça Mágica, fez as suas magias e eu sai a voar como um arrião no meio das nüvens!

Fonte: Acervo das autoras.

As narrativas têm como personagem principal Sura, uma menina moradora da Ilha do Ibo, na província de 
Cabo Delgado, e seus amigos, dois meninos o Nico e o Vitó e a menina Fina. Os quatro vão juntos para a escola, frequentam a mesma turma e são os ouvintes dos relatos das aventuras de Sura.

As aventuras de Sura são viabilizadas pela cabaça mágica que pertence a seu avô e, por meio de palavras mágicas, a menina é transportada a diferentes províncias em cada narrativa. $\mathrm{O}$ avô tem papel importante, pois além de ser o proprietário da cabaça mágica, é ele quem instrui a menina para a sua permanência nesse tempo fantástico: ela deve voltar antes do pôr do sol. Ele acredita que tudo o que nos rodeia tem poderes para nos ajudar, motivo pelo qual é necessário saber respeitar a natureza e todos os elementos.

Centradas no espaço geográfico de Moçambique, cada viagem e cada narrativa traz uma província, temporalmente focalizadas em três esferas: 1) tempo presente, onde a menina vive o seu cotidiano; 2) tempo do passado onde viveram seus antepassados e aqueles oriundos da província a ser demarcada pela narrativa; 3) tempo mítico na forma de histórias da cultura local, narrativas históricas e narrativas etiológicas.

Todos os títulos têm uma estrutura que se repete, iniciando com "Olá amigo", escrito em uma das diversas 
línguas faladas nas 11 províncias de Moçambique. Nesse primeiro momento, a menina protagonista é impelida a buscar soluções para uma problemática, na maioria das vezes, promovida pelo espaço escolar, que a levam viver a aventura a partir da cabaça mágica fornecida pelo avô; o segundo momento é vivido no espaço histórico da temática e da província em foco; e o terceiro momento, que é o retorno para sua comunidade e a divisão do vivido com seu avô e os amigos.

Desse modo, em cada província, a personagem conhece pessoas, histórias e elementos culturais que compõem - grande mosaico de seu país, e suas aventuras são registradas em um diário em que nos conta tudo o que vai aprendendo. Destaca-se que o gênero diário é demarcado pelo tipo de letra cursiva e a aventura histórica pela letra impressa. Podemos dizer que o tipo de letra e as ilustrações criam uma linha divisória que demarca a passagem espaço temporal da narrativa.

\section{As infâncias na Coleção Viagens com a cabaça mágica}

Infância é uma categoria histórica, em diálogo com dinâmicas sociais - uma realidade social construída e reconstruída historicamente. Enquanto um estado de espírito, a infância atravessa questões etárias, mas, nesse 
caso, atemo-nos às crianças e suas infâncias. Desse modo, ao longo deste texto pluralizaremos o substantivo, pensando que estaremos discutindo sobre uma infância plural, que habita um espaço geograficamente plural, embora as narrativas partam de suas singularidades (histórica, costumes, língua).

A infância, enquanto fenômeno social, tem compreensões relacionais e que são posicionadas. Elena Colonna (2009), quando discute a legitimidade de aplicar o conceito de "infância" em realidades externas ao contexto ocidental, de criação da concepção inicial de infância, conclui que:

Em geral, no continente africano, as ciências sociais, mas sobretudo as organizações internacionais, têm privilegiado o estudo das crianças "fora do lugar" (out of place), isso é, das crianças que não respondem à norma de infância da classe média europeia e norteamericana, depois universalizada, e que são por isso consideradas em situação de risco [...] Assim, as crianças e os jovens de África que quotidianamente brincam, cuidam dos irmãos, estudam, ajudam nas tarefas domésticas, trabalham, se organizam e lutam continuam a ser sistematicamente ocultados pela imagem das "crianças africanas pobres, esfomeadas e doentes", que os mass media e as organizações internacionais costumam propor à opinião pública. (COLONNA, 2009, p. 10 , grifo da autora) 
Reconhecer às crianças o estatuto de atores sociais plenos, e considerar narrativas de infâncias onde há interatividade entre crianças, a ludicidade, a fantasia como reconstrução do real no imaginário, elementos das culturas da infância e não somente narrativas de infâncias interrompidas. É alterar as formas de perceber as infâncias em contextos africanos e também mudanças de paradigmas na forma como compreendemos as experiências de países do sul global.

As crianças apresentadas na Coleção têm vida ativa e voz junto aos adultos. A protagonista Sura narra as histórias em uma dupla autoria dentro da narrativa, pois escreve em seu diário e conta ao seu avô e amigos cada uma de suas viagens mágicas. As crianças Fina, Nico e Vitó também são protagonistas, pois é desse convívio entre os quatro amigos que inquietações do cotidiano, seja da escola ou das brincadeiras, leva a menina ao mundo das fantásticas aventuras, na busca por conhecimentos sobre seu país, Moçambique, e as histórias dos povos que compõem essa nação.

A coleção contém, em sua elaboração, uma compreensão sobre as infâncias que farão a leitura das histórias. Os possíveis leitores dos livros são crianças de diferentes províncias, com culturas diversas e também línguas 
diferentes, que vivenciam uma realidade de contextos plurilinguísticos onde a língua portuguesa está em diálogo com as línguas autóctones e publicações bilíngues, ou com a presença de línguas autóctones integradas ao texto, compõem um projeto maior de valorização das línguas bantu de Moçambique, de forma que

[...] não só permitem a incorporação de formas de origem bantu [...] mas também dos universos culturais aos quais se vinculam tais formas, assim se instaurando, por sobre a unificação linguística que se vai operando, também essa relação mais íntima entre as línguas bantu e a portuguesa. (NGOMANE, 2010, s.p.)

Nessa composição plurilinguística, a Coleção emprega como estratégia introduzir no texto em língua portuguesa essas outras realidades linguísticas - e culturais - nacional, que é constituída pelas línguas bantu, incorporando no próprio texto termos, e não num glossário, e optando pela explicação do significado de cada termo na incorporação nas narrativas.

O conceito de africanidades, que propõe uma unidade, quando interpretado pela leitura da Coleção Viagens com a cabaça mágica, é compreendido como indissociada da multiplicidade cultural de África. Essa multiplicidade é evidenciada nas falas de Fina, a personagem de uma menina 
criança que "gosta muito de estudar a nossa História" (NEVES, 1996a), é curiosa sobre o passado. A proposição de diversidade na unidade e unidade da diversidade se prova nas histórias que Fina sabe sobre Moçambique, acrescidas pelas histórias que Sura narra ao retornar de cada uma de suas viagens.

Diante disso, apresentamos neste texto os três primeiros títulos da coleção, datados da década de 1990: 1) Na aldeia de Chai, em Cabo Delgado (NEVES, 1996a); 2) Em Inhambane fui apanhar tangerinas (NEVES, 1996b); e 3) Em Gaza fui saber sobre Ngungunhana (NEVES, 1999a).

O primeiro título que abre a Coleção é Na aldeia de Chai, em Cabo Delgado (NEVES, 1996a), que se passa na província onde Sura habita. O leitor é convidado a entrar na narrativa pelo chamamento "Olá amigo" em Kimwani, língua também falada pela personagem. A primeira viagem é provocada pela curiosidade de Sura, ao aprender na escola sobre os processos para independência de Moçambique, onde ouve falar de Chai, uma aldeia de Cabo Delgado em que ocorreu o primeiro tiro da luta de independência. Curiosa por saber mais sobre esse momento importante da história de Moçambique, ao chegar em casa, ela solicita ao avô que the deixe viajar 
até Chai. Ele autoriza e faz as recomendações necessárias para usar a Cabaça Mágica e o retorno ao pôr do sol.

Sura cai no meio de uma festa de dança Mapiko e uma senhora a acolhe e the explica sobre a dança em que apenas homens participam:

[...] há quem acredite que as máscaras usadas na dança do Mapiko, chamadas Lipiko, têm o poder de transformar aquele que as usa. No momento em que um homem enfia na cabeça a máscara, ele é possuído pelas forças da imaginação e torna-se um Lipiko. (NEVES, 1996a, s.p.)

A senhora que conta à Sura sobre os Makipo é quem contará as histórias que ouviu de seu pai sobre o dia 25 de setembro de 1964, quando foi dado o primeiro tiro da luta armada pela libertação nacional. Por suas palavras ficamos sabendo sobre a FRELIMO, grupo formado por pessoas que se uniram para "[...] lutar contra o colonialismo, as injustiças, o racismo" (NEVES, 1996a, s.p.), as quais eram chamadas de guerrilheiras, mas o governo português as denominava terroristas.

Sabe-se que a forma como anunciamos o mundo contém as relações de poder imbricadas em nossa sociedade, e o governo português, ao escolher considerar as pessoas integrantes da FRELIMO "terroristas", mobiliza o sentimento de que elas colocam em risco a sociedade, são uma ameaça 
ao Império Português além-mar. Porém, a senhora que narra a história à Sura não tem dúvidas sobre as intenções e a necessidade desse movimento de luta armada. Quando a menina se coloca contrária às guerras e lutas, ouvimos da senhora mais velha:

- Há alturas em que a luta parece a única solução. Temos de lutar para não morrermos. Temos de sacrificar a nossa vida para que os nossos filhos possam viver melhor. Foi isso que levou os camaradas dessa FRELIMO a lutar contra todas as injustiças. (NEVES, 1996a, s.p.)

Neste trecho, temos a marcação de outra FRELIMO, o que distingue a dos tempos atuais daquela nascida nos anos de 1960, com sede na Tanzânia e formada por pessoas que acreditavam e defendiam a "[...] igualdade entre as pessoas, que todos tínhamos valor e tudo era feito para melhorar a vida do povo. Acreditavam que a riqueza do nosso país devia ser dividida por todos os moçambicanos" (NEVES, 1996a, s.p.). A transição de um movimento de guerrilha para um partido que liderava o poder do Estado moçambicano esteve cheia de tensões e contradições (MENESES, 2015). Atualmente, segundo a personagem, acreditam que “[...] só porque são chefes, valem mais e têm direito a tudo e que o povo tem de sofrer" (NEVES, 1996a, s.p.). 
A senhora sábia, ao final da dança do Makipo, inicia outra história, que é de um tempo muito distante, quando uma avó da avó da senhora foi capturada pelos negreiros, pessoas que capturavam e traficavam homens, mulheres e crianças como escravizados/as. Com essa narrativa conhecemos as péssimas condições a que essas pessoas eram submetidas em uma longa viagem até o "porto de escravos", que se situava na Ilha do Ibo. Durante uma confusão, a moça consegue fugir e, para se salvar, "[...] correu muito, sem olhar para trás. Ouvia tiros, choros e gritos, mas não parou de correr. Enquanto corria só pedia a protecção dos antepassados e de todos os espíritos da natureza" (NEVES, 1996a, s.p.), até que retornou a sua casa sã e salva. Ao final da história, a senhora chama atenção para o fato de que a escravatura trouxe sofrimento a muitos povos de África e que hoje encontramos sofrimento devido às "guerras e a outras formas de escravidão" (NEVES, 1996a, s.p.).

Ao final da narrativa, Sura decide explorar o local para conhecer os animais e as plantas da região, ao que se assusta com o rugido de um Leão. Quando a menina questiona o leão do por que estar rugindo se não tinha dor em nenhum, o qual lhe conta a história que explica que eles rugem para assustar humanos. Enquanto trocava palavras com o leão, Sura percebe que o dia estava terminando e era hora de 
retornar para casa, onde poderá contar sua jornada para Fina, Vitó e Nico. Neste primeiro livro da coleção identificamos movimentos constantes de Sura, nas palavras de seu avô, "ver, ouvir e aprender" (NEVES, 1996a, s.p.).

Mesmo que ausente, na forma de personagens, temos múltiplas infâncias mobilizadas nessa primeira aventura de Sura. Infâncias interrompidas das crianças que foram apartadas de suas famílias durante as guerras - Guerra de Independência e a Guerra Civil - e retrocedendo no tempo as imagens de crianças destituídas de humanidade pelo projeto colonial europeu que sequestrou povos em territórios africanos. No entanto, há infâncias curiosas que frequentam o espaço escolar e que aprendem sobre sua história com protagonismo dos povos de Moçambique, infâncias que coexistem entre a modernidade e as tradições, pois Sura considera na mesma medida as palavras da "senhora sábia" e as do "Leão" em suas aprendizagens.

Em Inhambane fui apanhar tangerinas (1996b), segundo título, inicia com "Xoweni vangana!", que significa "Olá amigos" em chope, língua que se fala na província de Inhambane. Dessa vez, a viagem não é motivada por curiosidade escolar e sim por memórias sobre o sabor de tangerinas, a partir de um poema de José Craveirinha, declamado por Nico enquanto brincam na praia: 
Quizumba é quizumba

Mamba é mamba

Sapo é sapo

Juro que tangerinas de Inhambane são tangerinas de Inhambane

$\mathrm{Eu}$ adoro morder os gomos de sumo das tangerinas de Inhambane. (NEVES, 1996b, s.p.)

A poética de José Craveirinha faz Sura desejar ir à Inhambane para colher as tangerinas de lá. A menina cai no meio de uma dança onde os dançarinos "[...] vestiam peles, muitas fitas coloridas e panos. Tinham também peles nas pernas e azagaias e escudos. Quando batiam com o escudo no chão até parecia um tiro" (NEVES, 1996b, s.p.). Uma vovó, que lá estava, explicou a Sura que se tratava de Ngogo, onde os dançarinos eram denominados bassinhi e os músicos tocavam instrumentos chamados timbilas. Curiosa sobre a feitura das timbilas, a menina descobre que só sabem produzi-las grandes mestres, com muitos segredos, dentre eles, o fato de que a temperatura influencia o som e o calor desafina-a e que a árvore de nome Muenje, usada para fazer as teclas do instrumento, estava desaparecendo.

Para animá-la, Sura lhe pede que conte uma história e a vovó conta que Inhambane, há mais de 500 anos, era um centro de trocas de mercadorias, com pessoas vindas de diferentes lugares, como muçulmanos, hindus, portugueses, 
holandeses e muitos outros. No século $X X$, a indústria de pesca da baleia era muito forte no local, mas a extração era tanta que em menos de 30 anos as baleias desapareceram e, em 1924, as indústrias fecharam.

Findada essa história, a vovó contou sobre como viviam as pessoas no tempo colonial, onde era necessário pagar um tributo chamado "imposto de palhota" (NEVES, 1996b, s.p.) e, por isso, muitas pessoas de Inhambane tiveram de ir trabalhar em minas de ouro ou carvão no Transval, uma região na África do Sul (ZAMPARONI, 2012). Este imposto era muito alto e valia o preço de 90 dias de trabalho, sem nenhum gasto com alimentação e vestimenta. Com o passar do tempo, esse imposto se tornou per capita e, então, "para lutarem contra essa injustiça algumas famílias desmanchavam as suas palhotas e escondiam-se no mato. Outros diziam que as suas mulheres tinham falecido ou fugido e as palhotas estavam vazias" (NEVES, 1996b, s.p.).

Ao final da história, Sura e a vovó concluem que o povo da região já sofrera demais e que "era bom que agora todos compreendessem que não há pessoas, nem raças, nem tribos, nem povos que sejam mais ou menos importantes ou inteligentes que outros" (NEVES, 1996b, s.p.), para que todas as pessoas pudessem ter oportunidades e condições de viver bem. 
Como na primeira história da coleção, Sura explora a região e, ao passear à beira mar, perto dos manguezais, em Moçambique são chamados mangais, encontra um Dugongo que estava muito triste, pois haviam poucos de sua espécie. Sura pede que ele conte uma história e ficamos sabendo de um tempo em que viviam à costa tanto do lado da África como do lado da Ásia. Nessa época, muitas embarcações começaram a navegar por essas regiões e, devido ao medo ou à febre a que estavam submetidos muitos integrantes das tripulações, os marinheiros imaginavam que os dugongos eram mulheres peixes e chamavam-nas de sereias. Elas eram figuras mágicas e feiticeiras que levavam marinheiros para o fundo do mar. Como vingança, segundo a personagem de Dugongo, as pessoas "ainda hoje nos perseguem e nos matam" (NEVES, 1996b, s.p.).

Sura entristece-se com a história de Dugongo e percebe que estava tão distraída que o dia já estava terminando, então, corre para colher tangerinas e retornar para casa. No retorno, conta ao avô sobre a triste história dos dugongos, o qual sugere que a melhor forma de auxiliar era contando para muitas pessoas para que elas pudessem refletir sobre a necessidade de "[...] equilíbrio entre todos os seres e, se desaparece algum, isso pode afectar todos os outros seres" (NEVES, 1996b, s.p.). 
Quando leva as tangerinas para seus amigos, Nico, Fina e Vitó conversam e decidem fazer um cartaz enorme para colocar na escola e conscientizar todas as pessoas sobre os riscos de extinção dos dugongos, em uma proposta de intervenção direta sobre o presente que vivenciam.

Como resultado da viagem à Inhambane na história Em Inhambane Fui Apanhar Tangerinas (NEVES, 1996b), Fina, amiga de Sura, passa a acreditar que ela realmente tem viajado com a Cabaça Mágica de seu avô, não se tratando de sonhos, como pensava até então.

A multiplicidade de infâncias toma forma nessa segunda história com a representação de crianças que são agentes de transformação. O avô de Sura indica que informar as pessoas é uma forma de proteger os dugongos, mas é de Nico, Fina e Vitó e Sura a ideia de criar um cartaz. Assim, as quatro personagens infantis são (co)criadoras dos processos e detentoras de conhecimentos variados, mobilizados em espaços dentro e fora dos espaços escolares, como o caso de Nico quando declama um poeta nacional em uma brincadeira na areia da praia.

A busca por conhecer mais, o elemento da curiosidade possibilitada pela infância, está presente como característica de traço de personalidade da personagem Fina, que 
gostava muito de estudos sociais e queria saber sobre Ngungunhane e suas mulheres, enquanto Nico queria saber se ele, Ngungunhane, fora realmente mágico, e Vitó queria conhecer sobre as guerras em que Ngungunhane havia participado. Essa curiosidade toda leva Sura até a província de Gaza, na terceira história da coleção, Em Gaza fui saber sobre Ngungunhana (1999a), onde "Xewene vanghane"! é "Olá amigos" em Shangane.

Sura cai perto de uma casa cheia de gente em festa e uma jovem lhe conta que aquela era uma festa de lobolo, onde o noivo leva presentes aos pais da noiva para que possa levá-la com ele, como um registro do casamento. Em tempos anteriores, os casamentos sem lobolo não eram válidos, e caso o casamento termine, os pais da ex-noiva precisam devolvê-lo ao ex-noivo.

A jovem conta a Sura a história de Lhapfuta, uma mulher que se casou muitas vezes e depois desapareceu, perdendose o bucóssi - o nome dado ao valor do lobolo e deixando a família endividada, pois era necessário devolver todos os lobolo. Ela explicou que o bucóssi se altera com o tempo e já foram grandes anéis de ferro ou de cobre, bois, enxadas, chegando às libras quando muitos homens foram trabalhar no Transval, nas minas de ouro e carvão. 
Imersa no tema do lobolo, Sura recorda da curiosidade de Fina e pede à jovem que Ihe conte sobre Ngungunhane. Ele, Ngungunhane, vivia em um tempo em que os chefes tinham muitas mulheres para mostrarem que eram poderosos, e pela história que se conta, seu exército de 40.000 guerreiros foi derrotado pelos portugueses, em 1895, pois estavam fracos devido à fome. Depois de sua captura, Ngungunhane e sete das suas mulheres - Namatuco, Fussi, Patinina, Muzamussi, Maxxa, Hesipe e Deboni - foram exilados em uma das ilhas nos Açores. Somente no governo de Samora Machel, em 1985, os restos de Ngungunhane foram devolvidos a Moçambique.

Sura fica reflexiva sobre tudo que aprendera e é tirada de sua reflexão pelo chamado de uma vaca, que se oferece para contar uma história antiga. A Vaca escolhe falar sobre como nasceu o povo Bantu, "[...] um povo que veio das florestas do Congo, no centro do continente africano, e chegaram a Moçambique por volta dos anos 1700. Trouxeram a agricultura e a criação de gado e desenvolveram a cerâmica e o trabalho do ferro" (NEVES, 1999a, s.p.).

Na história contada pela Vaca, uma mulher deixa seus muitos filhos aos cuidados de um coelho enquanto busca comida, contudo, na ausência da mãe, um monstro aparece 
e engole todas as crianças e o coelho sai desesperado em busca da mulher. Ao encontrá-la e lhe contar a situação, ela se mune de um molhe de lenha, uma faca bem afiada e pedras para acender o fogo e sai à procura do monstro. Quando o encontra, ela também é engolida e lá dentro encontra seus filhos, outras pessoas, vacas e bois, cachorros. Como tinham fome, a mulher foi cortando bifes do monstro para alimentar todas as formas de vida que lá dentro estavam. O tempo foi passando, o monstro se sentia mal, mas nenhum animal sabia o porquê, até que caiu morto, e a mulher, com sua faca, abre a barriga do monstro para que todos os seres possam sair. Gratos por serem salvos:

[...] as pessoas disseram: - Ela será sempre a nossa conselheira.

Um homem prometeu:

- Eu caso com ela para a proteger e aos seus filhos.

Os cães afirmaram:

- Vamos ajudá-la a caçar e guardaremos a sua casa.

As vacas declararam:

- Vamos dar o nosso leite para alimentar os seus filhos.

Os bois disseram:

- Nós ajudaremos a trabalhar a terra. (NEVES, 1999a, s.p.)

A Vaca conclui a história dizendo que "assim surgiu o povo Bantu" e estava pronta para contar outra história a Sura, 
quando esta percebe que já entardecia e decide retornar para casa para que seu avô não se preocupe. Quando contou ao avô sobre suas aventuras, este refletiu sobre o importante papel das mulheres em todas as sociedades, concluindo que,

são sempre elas que nos alimentam nos primeiros tempos de vida. São elas que nos transmitem as primeiras impressões sobre o mundo, os valores, o amor. Por isso é tão importante que vão à escola, que votem, que discutam as leis, que participem em tudo, junto com os homens. Desprezar as mulheres é desprezar-se a si próprio e a toda a Humanidade. (NEVES, 1999a, s.p.)

Quando Sura partilhou sua história com Fina, Vito e Nico iniciou-se uma discussão entre eles sobre quem seria mais importante, homens ou mulheres, ao que Sura e Nico apenas observavam, pois consideravam que ambos são importantes de forma igual, elaborando uma crítica sobre a forma como essa relação se estabelece em diferentes sociedades.

Ao finalizar a apresentação dessas três narrativas, que correspondem aos três primeiros títulos da coleção Viagens com a cabaça mágica, compreende-se que a marca das infâncias mobilizadas nas histórias é a multiplicidade, em uma diversidade de formas de ser criança que têm como elemento comum a curiosidade infantil promovida pela ação 
da escola, das leituras de poemas, ou das brincadeiras lúdicas que levam Sura, Fina, Vito e Nico a imaginar e questionar sobre lugares distantes geograficamente ou temporalmente.

A curiosidade leva a escuta atenta das histórias contadas pela voz feminina em cada uma das três viagens de Sura, são mulheres de diferentes faixas etárias que partilham conhecimentos sobre os códigos sociais, rituais e eventos históricos. Essa partilha se dá em uma relação onde a criança não recebe transmissão passiva: Sura questiona, interroga, reelabora e quando junto de seus amigos produz novas narrativas, atua na realidade de seu tempo presente e também reconfigura as relações que estabelecem com o passado do país ao qual pertencem.

Há um movimento dialógico de ensinar e aprender pelas narrativas. Sura aprende em suas viagens com a cabaça mágica e, ao retornar, partilha seus conhecimentos com o avô, uma figura adulta, e com seus amigos, Fina, Vito e Nico. Não é o tempo de vida de Sura que Ihe garante conhecimentos suficientes sobre o mundo, é sua habilidade de se permitir viajar, é a curiosidade infantil que a mobiliza em cada uma das vezes que embarca na cabaça, e faz com que questione e ouça as pessoas e os animais fabulosos que encontra pelo caminho. 


\section{Sobre as crianças na coleção Viagens com a Cabaça Mágica}

As crianças, personagens das narrativas da Coleção Viagens com a Cabaça Mágica, não têm uma existência ingênua, ou apenas receptiva, mas, sim, inquieta, curiosa e ativa, capaz de elaborar questionamentos onde a imaginação, fantasia, criação e um olhar crítico sobre o passado são tramados em conjunto.

Sura e seus amigos recriam o mundo e a compreensão sobre Moçambique a partir de suas aventuras, elaboram então uma identidade moçambicana unificada pela diversidade ("Olá amigo" em diferentes línguas no início de cada livro da coleção) e Sura é então uma contadora de histórias.

As escolhas de temas que aparecem nos três títulos da coleção demonstram que Neves não subjuga a compreensão que as crianças leitoras têm, onde escravização, exploração, discriminação, guerras, religiosidades, tradição atravessam as narrativas. A história moçambicana é revisitada, na Coleção Viagens com a Cabaça Mágica, pela presença de pessoas mais velhas, que aparecem como anunciadoras, guardiãs do legado histórico e muito têm o que compartilhar com as crianças, e pelas próprias crianças que identificam, no presente, elementos do passado e os questionam. É o avô de Sura quem diz as palavras mágicas que tornam possíveis 
as viagens com a cabaça, mas é Sura quem viaja sozinha e faz a recolha das diversas narrativas que escuta atentamente.

A figura da criança como ativa nos processos de narrar está na linguagem verbal, como demonstramos nas análises dos títulos da coleção e está contida em características do projeto gráfico, que entendemos como elemento literário (MENEGAZZI; DEBUS, 2020), e que discutimos essa presença nos elementos de paratexto e na tipografia anteriormente.

A apresentação da Coleção Viagens com a Cabaça Mágica, que acontece no primeiro volume, $\mathrm{Na}$ aldeia de Chai, em Cabo Delgado (NEVES, 1996a), é feita pela personagem Sura. É ela quem se apresenta às leitoras e aos leitores da coleção e as informações que concede informam sobre a dinâmica do texto verbal ao longo de toda a coleção, a estrutura que apresentamos na seção anterior: uma história sobre a cultura local, uma narrativa histórica e uma narrativa etiológica.

Os livros, aqui analisados, não estão no Brasil, processo que está em curso pelo pesquisa Literalise/UFSC, grupo de pesquisa da Literatura Infantil e Juvenil relacionada às práticas de mediação literária em educação básica e superior, em pesquisa coordenada por Eliane Santana Dias Debus e Zâmbia Osório dos Santos, intitulada provisoriamente "Angelina Neves e a produção para infâncias". A importância de divulgar esta produção integra um movimento maior 
de publicizar produções africanas, mais especificamente de países como Moçambique, com experiências que nos aproximam e também nos distanciam, de forma a construir repertórios de leitoras de vivências diversas, com múltiplas possibilidades de existir como criança no espaço literário.

\section{Referências}

COLONNA, Elena. O lugar das crianças nos estudos africanos: reflexões a partir de uma investigação com crianças em Moçambique. Poiésis, [S.I.], v. 2, n. 4, p. 3-23, dezembro de 2009.

DEBUS, Eliane. Uma incursão pela poesia para infância em Moçambique. Mulemba. v. 13, n. 24. Rio de Janeiro: UFRJ. 2021.

DEBUS, Eliane; GUILA, Etelvino; SANTOS, Zâmbia Osório dos. Angelina Neves e a Coleção Histórias Tradicionais: de Coelhos, Hienas e Macacos. FAEEBA, v. 30 n. 62. Salvador, 2021.

GOMES, Simone Caputo. Literatura para crianças e jovens na África de língua portuguesa. Cátedra Digital, Rio de Janeiro, 2018. Disponível em: https://revista.catedra.puc-rio.br/index.php/literatura-para-criancas-ejovens-na-africa-de-lingua-portuguesa/ Acesso em: 27 jan. 2021.

MENEGAZZI, Douglas; DEBUS, Eliane. O design do livro de literatura para a infância: uma investigação do livro ilustrado contemporâneo. In: DEBUS, Eliane; SPENGLER, Maria Laura P.; GONÇALVES, Fernanda (Org.). Livro objeto: e suas (arti-e)manhas de construção. Curitiba: MercadoLivros, p. 15-50, 2020. MENESES, Maria Paula. Xiconhoca, o inimigo: Narrativas de violência sobre a construção da nação em Moçambique. Revista Crítica de Ciências Sociais, Coimbra, n. 106, p. 9-52, 2015.

NEVES, Angelina. Viagens com a cabaça mágica 1. Chai, Maputo: Coopimagem, 1996a.

NEVES, Angelina. Viagens com a cabaça mágica 2. Inhambane. Maputo: Coopimagem, 1996b. 
NEVES, Angelina. Viagens com a cabaça mágica 3. Gaza, Maputo: Coopimagem, 1999a.

NEVES, Angelina. Viagens com a cabaça mágica 5. Tete, Maputo: Coopimagem, 1999b.

NEVES, Angelina. Vamos contar? Maputo: Coopimagem, 2003.

NEVES, Angelina. O coelho e a hiena. Moçambique: Fundação Aga Khan, 2012a.

NEVES, Angelina. O coelho e o macaco. Moçambique: Fundação Aga Khan, 2012b.

NEVES, Angelina. Entrevista: Angelina Neves (Educação e Literatura Infanto-Juvenil) - Moçambique - 1a parte. Recanto das Letras, São Paulo, 4 abr., 2010. Disponível em: https://www.recantodasletras.com.br/ entrevistas/2177575. Acesso em: 31 maio 2020.

NEVES, Angelina e NUVUNGA, Natália. A capulana de D. Filomena: Livro didáctico para o ensino inicial 1ạ parte. Moçambique: Associação Progresso, 2013.

NGOMANE, Nataniel. Transculturação e representatividade linguística em Ungulani Ba Ka Khosa: um "comparatismo da solidariedade". OFICINA DO CES, Coimbra, n. 344, Coimbra, 2010.

OLIVEIRA, Maria Anória de Jesus. Um passeio panorâmico pela produção literária infantojuvenil moçamicana: autores e obras. A Cor das Letras, v. 12, n. 1. Feira de Santana 2011.

ZAMPARONI, Valdemir. De escravo a cozinheiro: colonialismo \& racismo em Moçambique. Salvador: EDUFBA: CEAO, 2012.

Eliane Santana Dias Debus possui doutorado em Lingüística e Letras pela Pontifícia Universidade Católica do Rio Grande do Sul (2001), Bolsa Recém-Doutor (PPGE/UFSC 2001-2004) e Pós-doutorado na Universidade do Minho (PT).

Professora associada do Departamento de Metodologia de Ensino e dos Programas de Pós-graduação em Educação e Estudos da Tradução da Universidade Federal de Santa Catarina (UFSC). 
Líder do grupo de pesquisa Literalise.

Lattes: http://lattes.cnpq.br/8529733083684329

ORCID iD: https://orcid.org/0000-0003-0555-2069

Zâmbia Osório dos Santos doutoranda em Educação pela Universidade Federal de Santa Catarina (UFSC). Bolsista da Coordenação de Aperfeiçoamento de Pessoal de Nível Superior (CAPES/DS).

Membra dos grupos de pesquisa Literalise e Alteritas/UFSC.

Lattes: http://lattes.cnpq.br/7598493553446804

ORCID iD: https://orcid.org/0000-0002-7301-6340 